\title{
LA DESHOJA EN EL MANEJO DE LA “BACTERIOSIS" DEL PALMITO DE PEJIBAYE (Bactris gasipaes) ${ }^{1}$
}

\author{
Carlos Arroyo-Oquendo ${ }^{2}$, Antonio Bogantes-Arias ${ }^{3}$, Jorge Mora-Urpi ${ }^{4}$
}

\begin{abstract}
RESUMEN
La deshoja en el manejo de la "Bacteriosis" del palmito de pejibaye (Bactris gasipaes). Entre los meses de mayo y setiembre del año 2004, se realizó un experimento en la Estación Experimental Los Diamantes en Guápiles, Costa Rica, en donde se estudió el efecto de la poda de hojas enfermas en el combate de la enfermedad conocida como "bacteriosis del palmito" de pejibaye, causada por la bacteria Pantoea stewartii y el hongo Fusarium sp., y la productividad de las plantas deshojadas nueve semanas después de la poda, así como las diferencias de comportamiento entre variedades. Se evaluaron cuatro variedades y cinco tratamientos de deshoja. La recuperación del follaje ocurrió en todos los tratamientos podados con igual velocidad, indicando que ésta fue alimentada por las reservas del tallo. Por otra parte, el tratamiento testigo (sin poda) mostró una producción significativamente menor de hojas que aquellos podados, lo cual indica que la deshoja estimuló una rápida recuperación del follaje. La deshoja "a cuatro hojas" permitió la recuperación del tallo al nivel del testigo no podado en cuatro semanas; y nueve semanas posteriores a la deshoja los tallos podados "a tres hojas" también habían recuperado el peso y la longitud del palmito al nivel del testigo. El número de hojas enfermas presente, nueve semanas después de la deshoja, correspondió con la drasticidad practicada de esa operación, a mayor deshoja menor número e intensidad de hojas enfermas. La variedad Diamantes-10 fue la que mostró el menor número de hojas enfermas, bajo todos los tratamientos.
\end{abstract}

Palabras clave: Bactris gasipaes, pejibaye, enfermedades, plagas, palmito.

\begin{abstract}
The role of defoliation in the management of the disease known as "bacteriosis of the pejibaye (Bactris gasipaes) heart of palm". An experiment was carried out in the Experimental Station "Los Diamantes" in Guapiles, Costa Rica, on the effect of pruning of diseased leaves on production and control of "bacteriosis of the pejibaye heart of palm", between May and September 2004,. According to the literature, the disease is caussed by the bacteria Pantoea stewartii in alliance with the fungus Fusarium sp. Five treatments of leaf pruning in four different varieties were evaluated. Nine weeks after defoliation recovery was the same in all five treatments, indicating that it depends on food reserves stored in the stem. On the other hand, the control (no pruning) treatment showed a significant lower production of new leaves than those pruned, indicating that pruning stimulated a rapid recuperation of the foliage. Pruning down to "four leaves" allowed the recuperation of the foliage to the level of the un-pruned plants in four weeks, while nine weeks after pruning, the stems pruned down to "three leaves" also recuperated the weight and length to the level of the control, while the number of sick leaves present nine weeks after pruning, correlated negatively with the number of leaves pruned off. The heavier the defoliation, the lower the number and severity of diseased leaves. The variety Diamantes-10 showed the lower number of infected leaves under all treatments.
\end{abstract}

Key words: Bactris gasipaes, pejibaye, diseases plagues, heart of palm.

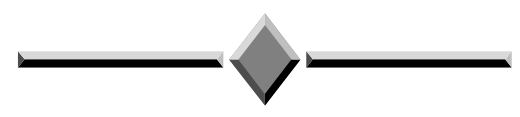

\footnotetext{
1 Recibido: 7 de noviembre, 2005. Aceptado: 5 de marzo, 2007. Trabajo patrocinado por el Consejo Nacional de Investigación y Tecnología (CONICIT).

2 Escuela de Zootecnia, Universidad de Costa Rica. Correo electrónico: carroyo@ cariari.ucr.ac.cr

3 Instituto Nacional de Innovación y Transferencia en Tecnología Agropecuaria (INTA), Estación Experimental Los Diamantes, Guápiles.

4 Escuela de Biología, Universidad de Costa Rica.
} 


\section{INTRODUCCIÓN}

En el año 1998, se alertó por primera vez sobre la presencia de una enfermedad en los cultivos de palmito de pejibaye, ahora conocida por los agricultores con el nombre de "bacteriosis del palmito", la cual se extendió por la zona norte de Costa Rica. Su presencia fue luego reportada en Bolivia, Ecuador y Panamá (Bohorquez 20045). Este problema fitosanitario vino a agravar la crisis económica que por los bajos precios internacionales atravesaba este cultivo en esa época. La disminución de la producción es muy variable dependiendo de la intensidad de la infección, puede alcanzar hasta más del 50\% (Sánchez et al. 2005).

La enfermedad es causada, según la literatura, por la bacteria Pantoea stewartii (Vargas-Cartagena et al. 2003; Zamora 2003; Araya 2004), aunque la identificación de la especie es aún controversial, se asocia con el hongo Fusarium sp. (Wang 2003) ${ }^{6}$. La enfermedad se inicia con la aparición de una pequeña mancha verde en los foliolos de las hojas. Esta mancha se extiende paulatinamente en forma longitudinal, paralela a las venas del foliolo, formando una banda. Esta banda es más visible por el lado superior. Dicha banda, al extenderse, se hace más notoria y cambia a un color café producto de la muerte o necrosis de los tejidos afectados. Las características inconfundibles de esta enfermedad son, además de la formación de las bandas mencionadas, una secreción gelatinosa y la aparición de pústulas café oscuro, ambas en el lado inferior de la hoja (Sánchez et al. 2005). La enfermedad es difundida horizontalmente en las plantaciones principalmente por el escarabajo Metamasius hemipterus y en menor grado por Rhynchophorus palmarum (Sánchez et al. 2005). Ambos escarabajos o "picudos", como son comúnmente conocidos, hacen el daño físico en las vainas de las hojas. Y la difusión vertical de la enfermedad, de las hojas superiores a las inferiores de la planta, se realiza por el agua de lluvia (VargasCartagena 2005).

5 BOHORQUEZ, J. 2000. Consulta sobre enfermedades nuevas del palmito. Ecovegetal. Guayaquil, Ecuador.

6 WANG, A. 2003. Identificación de Fusarium sp. Consulta. Programa de Protección de Cultivos. Programa de Protección de Cultivos, Escuela de Agronomía, Universidad de Costa Rica.
Solórzano et al. (2003), informan que los fungicidas e insecticidas probados no mostraron efectividad en el control de la enfermedad. Por esta razón, y porque se desea desarrollar un método de control amigable con el ambiente, se buscó una solución integral acorde con este principio, donde la poda de hojas enfermas surge como respuesta a esta necesidad.

Las actividades recomendadas para el combate integral de la bacteriosis (Sánchez et al. 2005) incluyen la deshoja parcial de las plantas enfermas. La poda de hojas o deshoja, tiene como objetivos: reducir la fuente de inóculo en la plantación, favorecer la aireación y penetración de la luz, contribuir a reducir la humedad relativa en el ambiente de la plantación, y disminuir el refugio que proveen las hojas a los escarabajos o "picudos". Como ésta es una práctica que mejora en forma inmediata la apariencia de la plantación enferma y es de bajo costo, los agricultores la adoptan con facilidad, aunque para ser efectiva en el combate de esta plagaenfermedad, requiere estar acompañada por las otras actividades recomendadas como: drenaje, fertilización, poda de cepa, trampeo de picudos y variedad tolerante.

Los resultados de esta práctica en esta instancia fueron evaluados no sólo por su acción sobre el problema fitosanitario, sino también por su efecto sobre la producción y calidad de palmito.

El objetivo de esta investigación fue determinar como afectan el rendimiento del palmito, los diferentes grados de deshoja, con el fin de reducir la infección en la plantación dado un tiempo de recuperación parcial o total del follaje, así como averiguar si existen diferencias de respuesta entre variedades a esta práctica.

\section{MATERIALES Y MÉTODOS}

\section{Descripción del área de investigación}

El experimento se realizó entre mayo y setiembre del 2004 en la Estación Experimental Los Diamantes, ubicada en el cantón de Pococí, Limón, Costa Rica a $250 \mathrm{msnm}$. Los datos climáticos durante el período del estudio se resumen en el Cuadro 1. La precipitación promedio anual es de $4.500 \mathrm{~mm}$, para dicha región. 
Cuadro 1. Promedio de datos climáticos en el período del estudio. Estación Experimental Los Diamantes, Guápiles, Limón, Costa Rica. Mayo-setiembre 2004.

\begin{tabular}{lcc}
\hline Mes & $\begin{array}{c}\text { Precipitación } \\
(\mathbf{m m})\end{array}$ & $\begin{array}{c}\text { Temperatura media } \\
\left({ }^{\circ} \mathbf{C}\right)\end{array}$ \\
\hline Mayo & 986,4 & 23,9 \\
Junio & 221,4 & 24,2 \\
Julio* & 111,4 & 24,2 \\
Agosto & 313,8 & 24,2 \\
Setiembre & 270,8 & 24,4 \\
\hline
\end{tabular}

Fuente: Estación Experimental Diamantes-INTA. *Faltan datos del 10 al 20 de julio. (La precipitación estimada para ese mes corresponde a $167,1 \mathrm{~mm})$.

El suelo en la parcela experimental corresponde a un inceptisol, el cual se clasifica como Adic Oxyaquic Dystrendeps, de textura franco arenosa y su composición química se presenta en el Cuadro 2.

\section{Tratamientos y diseño experimental}

Para el establecimiento de los tratamientos se utilizaron unas cepas de la plantación de palmito con cinco años de edad, con plantas de cuatro variedades de pejibaye para palmito: tres sin espinas, Diamantes-1 (de ascendencia Utilis-Guatuso), Diamantes-10 (de ascendencia Yurimaguas) y Diamantes-20 (de ascendencia Tuira-Darién); y una con espinas (Utilis-Tucurrique), con una densidad de siembra de 10.000 plantas por hectárea ( $2 \mathrm{~m}$ entre hileras x 0,5 m entre plantas).

Se establecieron seis tratamientos de poda de hoja (deshoja) en cuatro variedades de palmito de pejibaye (Figura 1 y Cuadro 3).
Los tratamientos de poda de hojas se aplicaron al tallo de mayor desarrollo de cada cepa que hubiera alcanzado no menos de siete $\mathrm{cm}$ de diámetro en la base (a $10 \mathrm{~cm}$ del suelo).

El diseño experimental fue de parcela dividida con seis tratamientos y tres repeticiones en cada tratamiento. La variedad de palmito se asignó a la parcela grande y los tratamientos de poda de hoja a la pequeña. La parcela útil constaba de cinco estípites o tallos obtenidos de igual número de cepas.

Para el análisis estadístico se utilizó el paquete de análisis estadístico SAS del año 2002. Las comparaciones de medias se realizaron utilizando la prueba Waller-Duncan, con una significancia $\mathrm{P}(\alpha \leq 0,05)$.

Se hicieron dos fertilizaciones con $50 \mathrm{~g}$ por planta de la fórmula comercial 18-5-15-6-1,2 (30 días antes y uno después de la poda de hojas). Los tallos tratados se cosecharon nueve semanas después.

Las variables evaluadas fueron:

1. Diámetro del tallo $(\mathrm{cm})$ al inicio y nueve semanas después (medida hecha en la base del tallo a una altura de $10 \mathrm{~cm}$ del suelo).

2. Número total de hojas a las cuatro y nueve semanas después de aplicados los tratamientos.

3. Número de hojas con síntomas de enfermedad nueve semanas después de la deshoja.

4. Intensidad de la enfermedad, nueve semanas después de la poda. Se estimó de forma visual con base en una escala de 0 a 3 en donde: $0=$ ausente, $1=$ inicial (menos del $10 \%$ de área foliar), $2=$ intermedia $(11-25 \%)$ y $3=$ avanzada $(\geq 26 \%)$.

Cuadro 2. Análisis químico de suelo. Estación Experimental Los Diamantes, Guápiles, mayo 2004.

\begin{tabular}{|c|c|c|c|c|c|c|c|c|c|c|c|c|c|}
\hline \multirow{2}{*}{$\begin{array}{c}\mathbf{p H} \\
\mathrm{H}_{2} \mathrm{O}\end{array}$} & \multicolumn{4}{|c|}{$\operatorname{cmol}(+) / \mathbf{l}$} & \multirow[b]{2}{*}{ CICE } & \multirow[b]{2}{*}{$\mathrm{P}$} & \multicolumn{6}{|c|}{$\mathrm{mg} / \mathrm{l}$} & \multirow{2}{*}{$\begin{array}{r}\% \\
\text { M.O }\end{array}$} \\
\hline & $\mathrm{Ca}$ & $\mathrm{Mg}$ & K & Acidez & & & $\mathrm{Cu}$ & $\mathrm{Fe}$ & $\mathrm{Mn}$ & $\mathrm{Zn}$ & B & S & \\
\hline 5,2 & 4,66 & 1,58 & 0,45 & 0,58 & 7,27 & 23,1 & 15,8 & 202 & 11,4 & 0,94 & 1,22 & 6,85 & 9,96 \\
\hline
\end{tabular}




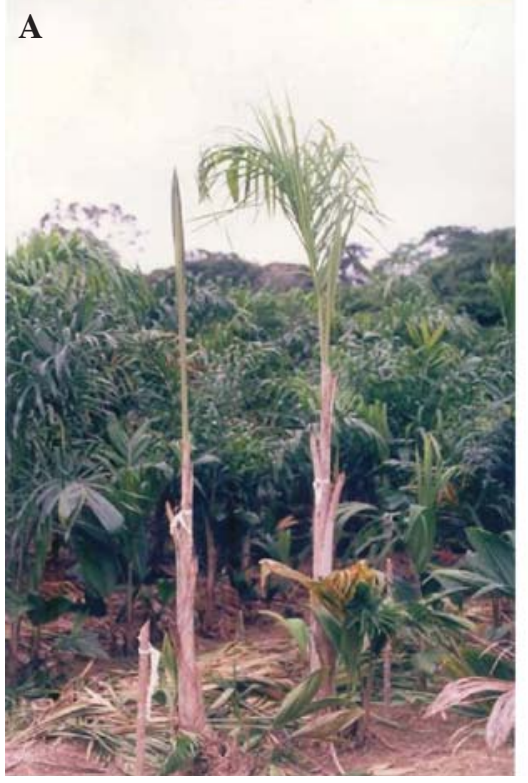

Planta con hoja guía y planta con una hoja

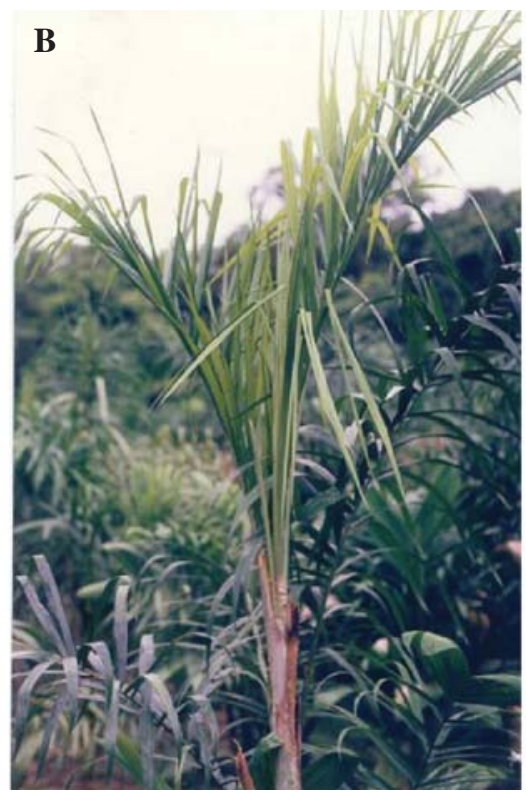

Planta con dos hojas

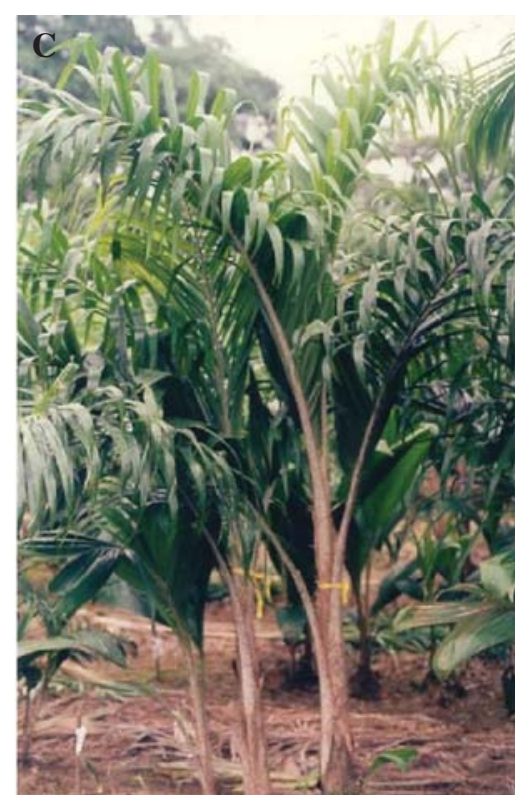

Planta con cuatro hojas

Figura 1. Fotografías que muestran las plantas de pejibaye luego de haber aplicado los tratamientos de deshoja. Estación Experimental Los Diamantes, Guápiles, Limón, Costa Rica. Mayo-setiembre 2004.

Cuadro 3. Variedades de pejibaye con los tratamientos de deshoja. Estación Experimental Los Diamantes, Guápiles, Limón, Costa Rica. Mayo-setiembre 2004.

\begin{tabular}{llc}
\hline Variedad & \multicolumn{1}{c}{$\begin{array}{c}\text { Tratamiento de } \\
\text { deshoja* }\end{array}$} & $\begin{array}{c}\text { Promedio de hojas } \\
\text { podadas/tratamiento }\end{array}$ \\
\hline & 1. Testigo sin podar & 0 \\
Diamantes 1 & 2. planta con 4 hojas & 1,41 \\
Diamantes 10 & 3. planta con 3 hojas & 2,66 \\
Diamantes 20 & 4. planta con 2 hojas & 3,27 \\
Tucurrique & 5. planta con 1 hoja & 4,07 \\
& 6. planta con hoja guía** & 5,19 \\
\hline
\end{tabular}

*Número de hojas que permanecen en el tallo después de la deshoja.

**Planta con solo la hoja apical sin abrir, conocida como "candela" u hoja guía.

5. Diámetro en cm del palmito foliar y caulinar*.
6. Longitud en cm del palmito foliar y caulinar*.

7. Peso en g del palmito foliar y caulinar*.

\section{RESULTADOS Y DISCUSIÓN}

El número promedio de hojas presentes en tallos del diámetro utilizado en este estudio $(\geq 7 \mathrm{~cm})$ fue de 5,19 . La "hoja guía" estuvo sana así como la primera hoja recién abierta. Las demás hojas, si la incidencia de la enfermedad fue alta, generalmente mostraron la infección, en grado creciente en el orden descendiente del ordenamiento foliar. Por esta razón la deshoja parcial incluye preferentemente las hojas inferiores o "bajeras" como dicen los agricultores.

La recuperación del follaje después de la deshoja, hasta alcanzar de nuevo el número de hojas normal que corresponde al tallo en cuestión, se asumió que seguirá

\footnotetext{
* = El palmito tiene dos sectores claramente definidos: uno formado solo por hojas o partes de ella (palmito foliar) y otra por el sector suave apical sólida del tallo (palmito caulinar).
} 
un patrón congruente con el número de hojas que se le permitió retener, hasta alcanzar su reposición total (Arroyo y Mora Urpí 2003b). El objetivo fue determinar cómo afecta las diferentes deshojas el rendimiento del palmito, con el fin de reducir la infección en la plantación dado un tiempo de recuperación parcial o total del follaje, así como si la poda, contribuye en algún grado al control de la enfermedad.

En primer término se presentarán los resultados en forma global reuniendo los datos de las cuatro variedades (Cuadros 4, 5 y Figuras 2, 3, 4 y 5) y en segundo término las variedades individualmente (Figuras 6 y 7) en relación con los cinco tratamientos de poda de hojas.

\section{Recuperación del número de hojas cuatro y nueve semanas después de la poda}

El número de hojas, un mes después de la poda mostró diferencias estadísticamente significativas entre todos los tratamientos excepto entre el testigo y la planta que retuvo cuatro hojas (Cuadro 4). Lo que esto indica es que la poda a "cuatro hojas" se recuperó en este lapso de tiempo hasta alcanzar en número de hojas al testigo no podado; más no alcanza ese número de hojas en los tratamientos más drásticas, en donde, el número total de hojas muestra una gradiente correspondiente a la severidad de la poda se mantuvo. Pero, la recuperación del follaje, en cuanto

Cuadro 4. Promedio global de las cuatro variedades bajo seis tratamientos. Estación Experimental Los Diamantes, Guápiles, Costa Rica. Mayo-setiembre, 2004.

\begin{tabular}{|c|c|c|c|c|c|c|}
\hline \multirow[b]{2}{*}{ Variables evaluadas } & \multicolumn{6}{|c|}{ Tratamiento } \\
\hline & $\begin{array}{c}\text { Testigo } \\
\text { (Sin Poda) }\end{array}$ & $\begin{array}{c}\text { Planta conserva } \\
4 \text { hojas }\end{array}$ & $\begin{array}{c}\text { Planta conserva } \\
3 \text { hojas }\end{array}$ & $\begin{array}{c}\text { Planta conserva } \\
2 \text { hojas }\end{array}$ & $\begin{array}{c}\text { Planta conserva } \\
1 \text { hoja }\end{array}$ & $\begin{array}{c}\text { Planta conserva } \\
\text { solo hoja guía }\end{array}$ \\
\hline $\mathrm{N}^{\mathrm{o}}$ de hojas podadas al inicio & $0,00 \mathrm{f}^{*}$ & $1,41 \mathrm{e}$ & $2,66 \mathrm{~d}$ & $3,27 \mathrm{c}$ & $4,07 \mathrm{~b}$ & $5,19 \mathrm{a}$ \\
\hline $\mathrm{N}^{\circ}$ de hojas a las cuatro semanas & s $\quad 6,15$ a & $5,80 \mathrm{a}$ & $4,65 \mathrm{~b}$ & $3,86 \mathrm{c}$ & $2,71 d$ & $1,81 \mathrm{e}$ \\
\hline $\mathrm{N}^{\mathrm{o}}$ de hojas a las nueve semanas & s 7,06 a & $7,02 \mathrm{a}$ & $6,21 \mathrm{~b}$ & $5,59 \mathrm{c}$ & $4,48 \mathrm{~d}$ & $3,36 \mathrm{e}$ \\
\hline Diámetro de planta al inicio & $9,05 \mathrm{a}$ & $9,22 \mathrm{a}$ & $9,13 \mathrm{a}$ & $9,13 \mathrm{a}$ & $8,92 \mathrm{a}$ & $8,87 \mathrm{a}$ \\
\hline $\begin{array}{l}\text { Diámetro de planta a las } \\
\text { nueve semanas }\end{array}$ & $11,42 \mathrm{a}$ & 11,63 a & 11,39 a & $11,21 \mathrm{ab}$ & $10,70 \mathrm{~b}$ & $9,78 \mathrm{c}$ \\
\hline $\begin{array}{l}\mathrm{N}^{\circ} \text { hojas enfermas a las } \\
\text { nueve semanas }\end{array}$ & $3,72 \mathrm{a}$ & $3,29 \mathrm{~b}$ & $3,11 \mathrm{~b}$ & $2,10 \mathrm{c}$ & $1,81 \mathrm{c}$ & $1,04 \mathrm{~d}$ \\
\hline $\begin{array}{l}\text { Intensidad de enfermedad } \\
\text { a las nueve semanas }\end{array}$ & $1,94 \mathrm{a}$ & $1,88 \mathrm{a}$ & $1,61 \mathrm{~b}$ & $1,16 \mathrm{~cd}$ & $1,35 \mathrm{cb}$ & $0,91 \mathrm{~d}$ \\
\hline $\begin{array}{l}\text { Diámetro del palmito foliar } \\
\text { a la cosecha }\end{array}$ & $28,04 \mathrm{ab}$ & $28,30 \mathrm{ab}$ & 29,08 a & $27,92 \mathrm{ab}$ & $26,79 \mathrm{bc}$ & $25,66 \mathrm{c}$ \\
\hline $\begin{array}{l}\text { Diámetro del palmito } \\
\text { caulinar a la cosecha } \\
\text { Peso del palmito foliar a }\end{array}$ & $47,24 a b$ & $47,44 \mathrm{ab}$ & 48,13 a & $46,47 \mathrm{ab}$ & $45,41 \mathrm{~b}$ & $42,32 \mathrm{c}$ \\
\hline la cosecha & $267,45 \mathrm{a}$ & 272,58 a & 276,73 a & 255,19 a & $218,04 \mathrm{~b}$ & $186,23 \mathrm{~b}$ \\
\hline $\begin{array}{l}\text { Peso del palmito caulinar } \\
\text { a la cosecha }\end{array}$ & $81,57 \mathrm{ab}$ & $74,84 \mathrm{ab}$ & 89,91 a & 95,22 a & $67,23 \mathrm{bc}$ & $48,24 \mathrm{c}$ \\
\hline $\begin{array}{l}\text { Longitud palmito foliar a } \\
\text { la cosecha }\end{array}$ & $41,12 \mathrm{a}$ & $40,12 \mathrm{a}$ & $41,28 \mathrm{a}$ & $41,21 \mathrm{a}$ & $37,08 \mathrm{~b}$ & $34,62 \mathrm{~b}$ \\
\hline $\begin{array}{l}\text { Longitud palmito caulinar } \\
\text { a la cosecha }\end{array}$ & $4,04 \mathrm{a}$ & $4,35 \mathrm{a}$ & $4,29 \mathrm{a}$ & $4,35 \mathrm{a}$ & $3,70 \mathrm{a}$ & $2,69 \mathrm{~b}$ \\
\hline
\end{tabular}

*a b c d e f= Valores medios con letra distinta en sentido horizontal son estadísticamente diferentes (Duncan $\mathrm{P} \leq 0,05)$. 
Cuadro 5. Número total de hojas de pejibaye a las cuatro y nueve semanas después de la deshoja y las diferencias entre éstas y el número promedio de hojas iniciales. Estación Experimental Los Diamantes, Guápiles, Limón, Costa Rica. Mayo-setiembre 2004.

\begin{tabular}{lcccccc}
\hline & Testigo & Cuatro hojas & Tres hojas & Dos hojas & Una hoja & Hojas guía* \\
\hline \# hojas iniciales & 5,19 & 4 & 3 & 2 & 1 & 0 \\
Cuatro semanas & 6,15 & 5,80 & 4,65 & 3,86 & 2,71 & 1,81 \\
Diferencia & 0,96 & 1,80 & 1,65 & 1,86 & 1,71 & 1,81 \\
& & & & & \\
Nueve semanas & 7,06 & 7,02 & 6,21 & 5,59 & 4,48 & 3,36 \\
Diferencia & 1,91 & 3,02 & 3,21 & 3,59 & 3,48 & 3,36 \\
\hline
\end{tabular}

* = hoja sin abrir.

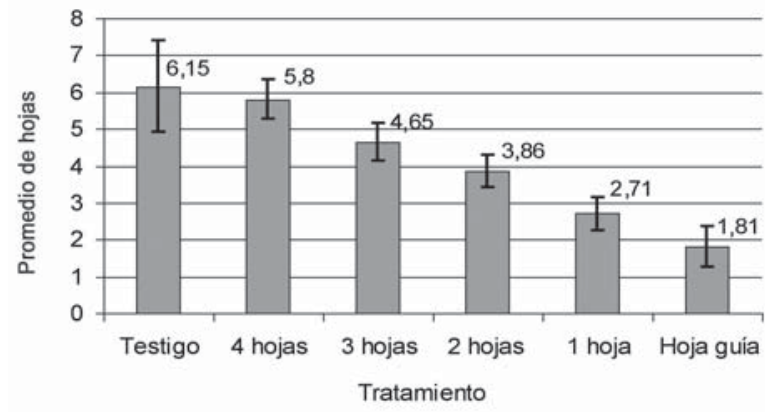

Figura 2. Número promedio del total de hojas cuatro semanas después de la poda. Estación Experimental Los diamantes Guápiles, Limón, Costa Rica, 2004.

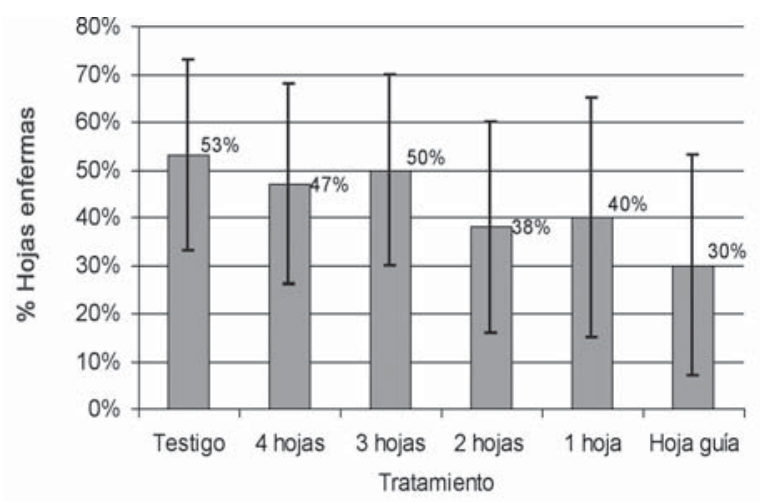

Figura 4. Porcentaje de hojas enfermas con respecto al número total de hojas, nueve semanas después de la poda. Estación Experimental Los Diamantes, Guápiles, Limón, Costa Rica. 2004.

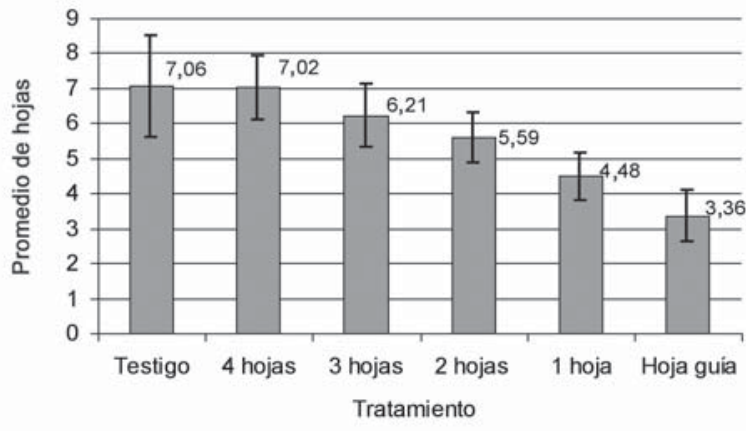

Figura 3. Número promedio del total de hojas a las nueve semanas después de la poda Estación Experimental Los diamantes Guápiles, Limón, Costa Rica, 2004.

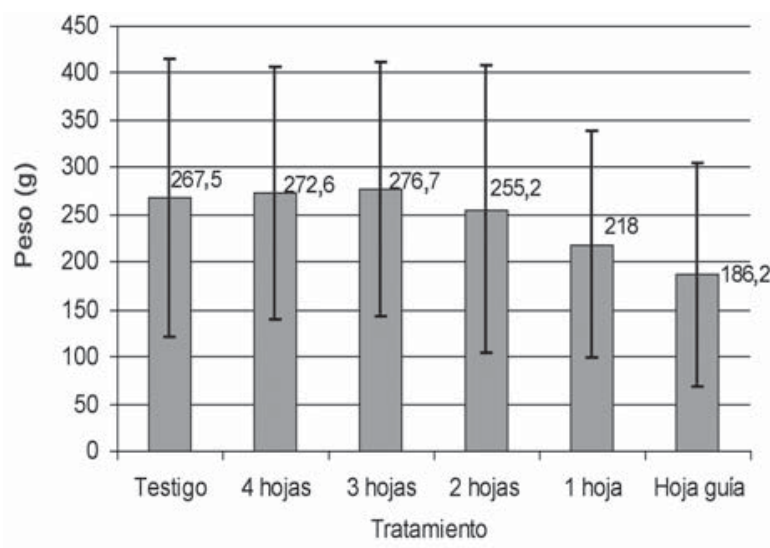

Figura 5. Peso del palmito foliar de pejibaye, nueve meses después de la poda (g). Estación Experimental Los Diamantes, Guápiles, Limón, Costa Rica. 2004.

AGRONOMÍA MESOAMERICANA 18(1): 129-138. 2007 


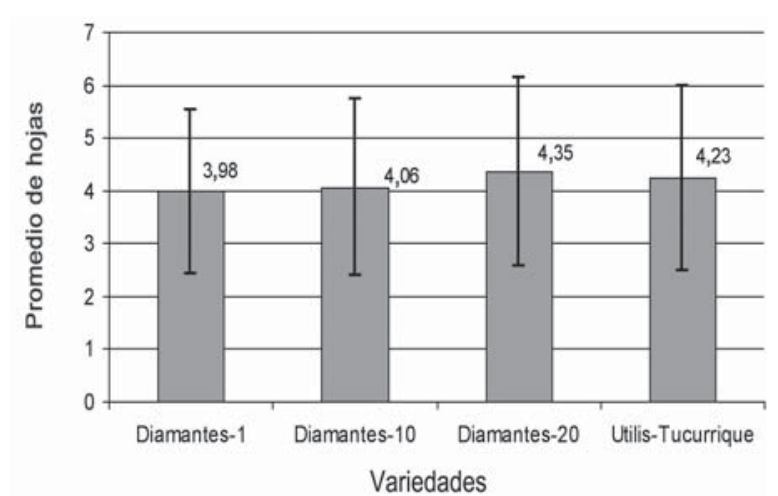

Figura 6. Número promedio de hojas por variedad, cuatro semanas después de la poda. Estación Experimental Los Diamantes, Guápiles, Limón, Costa Rica. 2004.

al número de hojas nuevas, en todos los tratamientos es prácticamente igual (Cuadro 5). El número de hojas que permaneció en el tallo no mostró influencia sobre la producción de nuevas hojas producidas, lo cual es contrario a lo que podría ser esperado. Esto indica, según Mora-Urpí (1999), que son las reservas de nutrientes (alimento) acumulado en el tallo las que determinan esta respuesta. En este caso los tallos de todos los tratamientos tenían diámetros semejantes, inducen respuestas semejantes, esto es, igual producción de follaje, lo cual representa igual capacidad de almacenar reservas y por lo tanto por esta razón no hubo diferencia en el número de nuevas hojas producidas por los tratamientos con cuatro, tres, dos, uno y la hoja guía que es respectivamente 1,$80 ; 1,65 ; 1,86$; 1,71 y 1,81 hojas.

Por otra parte, el testigo sin poda mostró comparativamente con estos un crecimiento de 0,96 hojas, que resultó significativamente menor (Cuadro 5). Este último aspecto parece indicar que la operación de poda estimuló una mayor rapidez en la producción de nuevo follaje sin importar cuán severa haya sido la deshoja. También es de suponer que la poda a "cuatro hojas", un mes después de la operación, ha recuperado la condición de cosecha del palmito con características normales de peso, longitud y calidad para su edad.

No ocurrió lo mismo respecto al aumento de diámetro del tallo, en donde los tallos con cuatro y tres hojas

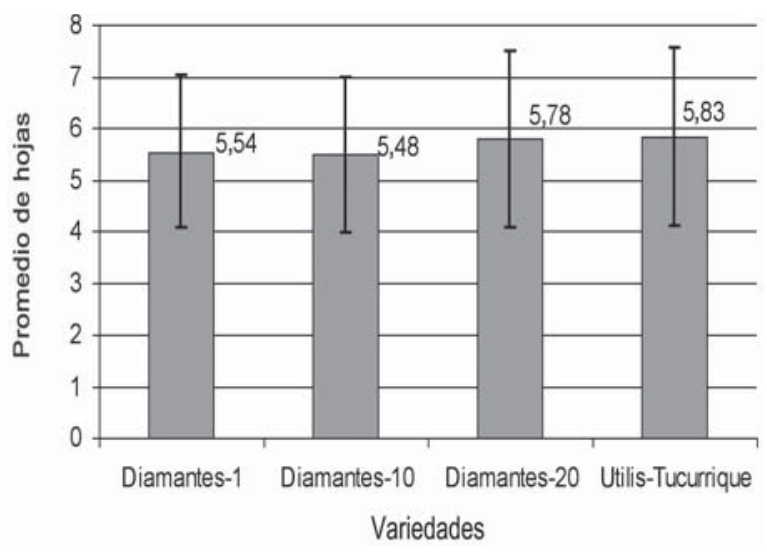

Figura 7. Número promedio de hojas de pejibaye de cuatro variedades, nueve semanas después de la poda. Estación Experimental Los Diamantes, Guápiles, Limón, Costa Rica. 2004.

mostraron a las nueve semanas un aumento igual al testigo sin poda $(2,41 ; 2,26$ y $2,37 \mathrm{~cm}$, respectivamente) en tanto que los tallos con una hoja y hoja guía aumentaron su diámetro significativamente menos $(1,78$ y 0,91 respectivamente) (Cuadro 4). En esta variable se refleja una correlación positiva entre el área foliar y el diámetro del tallo, como es de esperar, tal como está reportado en la literatura (Arroyo y Mora Urpí 2003a).

Como existió una alta correlación positiva entre el diámetro del tallo y peso del palmito foliar $\left(\mathrm{r}^{2}=0,73\right.$ (Arroyo y Mora-Urpí 2002)), puede anticiparse que tallos podados a cuatro y tres hojas pesan igual al testigo sin poda y que aquellos podados a una hoja y hoja guía resulten significativamente inferiores, lo cual resulta cierto.

De los resultados anteriores se puede concluir que la deshoja o poda de tallos con el diámetro indicado, aproximadamente nueve semanas después, se han recuperado hasta alcanzar un rendimiento similar al testigo de palmito. Así, la deshoja parcial no afectó el rendimiento del palmito cosechado dos meses más tarde $\mathrm{y}$, en la poda a cuatro hojas, un mes después ya se ha recuperado.

\section{Relación deshoja - enfermedad}

La relación de la deshoja y el estado de la enfermedad al cabo de nueve semanas después de la deshoja, el testigo (sin poda), mostró un 53\% de hojas enfermas 
y el tratamiento más drástico de deshoja, en el cual solo permanece inicialmente la hoja guía, mostró un $30 \%$ de hojas enfermas. En términos generales, hubo relación entre el número de hojas enfermas presentes, nueve semanas posteriores a la deshoja $(50,49$ y $37 \%$ respectivamente) con la disminución proporcional del número de hojas que permanecen al deshojar (Cuadro 4, Figuras 2 y 4 ).

Con el tiempo, la infección aumentó hasta alcanzar de nuevo el nivel del testigo por causa de la reinfección que tendrá lugar, inducida por los vectores (escarabajos y lluvia), si no se toman las medidas pertinentes para evitarlo, contenidas en las recomendaciones establecidas. El tiempo requerido para que el grado de infección alcance de nuevo el nivel del testigo, si sólo se practica la deshoja, variará según las condiciones ecológicas de la plantación especialmente en lo referente a humedad y nutrición; y aún no se ha elaborado una curva que muestre su progreso bajo ninguna condición de ambiente. Debido a que la infección progresa paulatinamente en la hoja, ésta permanece funcional, en proporción a la intensidad de la infección.

El tiempo que la deshoja ha de permanecer funcional será variable, según el ambiente le sea más o menos favorable al progreso de la enfermedad (básicamente el grado de humedad). Una hoja sana, en tallos de esta edad, tiene un ciclo de vida en la variedad criolla (Utilis-Tucurrique) de cinco a seis meses (Sánchez 1981). Una hoja ligeramente atacada puede completar su ciclo de vida normal, en tanto, que bajo condiciones de alta humedad la enfermedad progresa rápidamente cubriendo la mayor parte de su área, acortando drásticamente su periodo de vida útil.

En el combate de la enfermedad, la verdadera lucha se centra en evitar la reinfección, lo cual es un tema a tratar por separado, aquí sólo se trata uno de los componentes del tratamiento integral, el cual además de la deshoja, como ya se indicó, abarca drenaje, fertilización, poda de cepa, trampeo de picudos y variedad. Por lo tanto, si se detiene la reinfección en alguna medida (básicamente a través de deshoja y trampeo de picudos) la velocidad del aumento de la incidencia de la enfermedad será menor en igual proporción.
Por tal razón, es difícil ofrecer recomendaciones de carácter general sobre la frecuencia que deben realizarse las deshojas. Sin embargo, basado en las observaciones realizadas sobre el efecto de la deshoja en la producción, se recomienda que la poda sólo se realice ocasionalmente en aquellas hojas que muestran un avance notorio de la enfermedad, de manera selectiva o en su defecto, un par de veces al año, también en forma selectiva. Como la ocurrencia de días muy lluviosos ("temporales") favorece la propagación e intensidad de la enfermedad (Sánchez et al. 2005) las podas resultarían más efectivas inmediatamente después de esos períodos.

\section{Comportamiento de las variedades}

El comportamiento de respuesta a la deshoja difiere entre variedades. Aquellas que produjeron un desarrollo foliar pospoda más rápido fueron Diamantes-20 y Utilis-Tucurrique (Figuras 6 y 7) ambas de germoplasma nacional. El menor número de hojas enfermas lo muestran Diamantes-10, derivada de germoplasma del Alto Amazonas, seguida por Diamantes-20, creada de germoplasma de Darien-Panamá (Cuadro 6). El tratamiento-1 (testigo) muestra cuál fue la situación "natural" en la plantación y esa relación entre variedades y la enfermedad se mantuvo a través de cuatro tratamientos de deshoja (una, dos, tres y cuatro hojas), pero varió en el tratamiento-6 (hoja guía) en donde Diamantes-1 se muestra como el más afectado y Diamantes-20 y Utilis-Tucurrique aparecen igualmente susceptibles. Diamantes-10 es consistentemente la variedad menos susceptible a la enfermedad (Cuadro 6), lo cual ha sido establecido en otras investigaciones (Sánchez et al. 2005).

\section{CONCLUSIONES}

La deshoja debe ser moderada, limitándola a las hojas enfermas en grados medio a avanzado. Las hojas poco afectadas no deben podarse.

La frecuencia de la poda estará indicada por el grado de infección que muestre la plantación. 
Cuadro 6. Número promedio de hojas enfermas en palmito de pejibaye, desviación estándar para cada variedad según el tratamiento. Estación Experimental los Diamantes, Guápiles, Limón, Costa Rica. 2004.

\begin{tabular}{llcc}
\hline Variedad & Tratamiento & $\begin{array}{c}\text { Promedio } \\
\text { de hojas } \\
\text { enfermas }\end{array}$ & $\begin{array}{c}\text { Desviación } \\
\text { estándar }\end{array}$ \\
\hline Diamantes-1 & Testigo & 4,00 & 0,87 \\
Diamantes-1 & 4 hojas & 3,78 & 1,09 \\
Diamantes-1 & 3 hojas & 3,84 & 1,28 \\
Diamantes-1 & 2 hojas & 2,20 & 1,03 \\
Diamantes-1 & 1 hoja & 1,91 & 0,83 \\
Diamantes-1 & Hoja guía & 1,82 & 0,87 \\
Diamantes-10 & Testigo & 3,14 & 1,41 \\
Diamantes-10 & 4 hojas & 2,00 & 1,13 \\
Diamantes-10 & 3 hojas & 2,20 & 0,94 \\
Diamantes-10 & 2 hojas & 1,13 & 1,30 \\
Diamantes-10 & 1 hoja & 1,00 & 0,95 \\
Diamantes-10 & Hoja guía & 0,50 & 0,71 \\
Diamantes-20 & Testigo & 3,40 & 1,29 \\
Diamantes-20 & 4 hojas & 3,50 & 1,09 \\
Diamantes-20 & 3 hojas & 2,60 & 1,18 \\
Diamantes-20 & 2 hojas & 2,14 & 0,95 \\
Diamantes-20 & 1 hoja & 1,29 & 0,99 \\
Diamantes-20 & Hoja guía & 0,93 & 0,73 \\
Utilis-Tucurrique & Testigo & 4,40 & 1,12 \\
Utilis-Tucurrique & 4 hojas & 4,23 & 1,42 \\
Utilis-Tucurrique & 3 hojas & 4,00 & 0,71 \\
Utilis-Tucurrique & 2 hojas & 3,17 & 0,94 \\
Utilis-Tucurrique & 1 hoja & 2,87 & 0,83 \\
Utilis-Tucurrique & Hoja guía & 0,92 & 0,67 \\
\hline & & &
\end{tabular}

La deshoja drástica reduce en igual medida el rendimiento del tallo en cuestión.

La poda que permite retener tres hojas al tallo, recupera el follaje a su condición normal en aproximadamente dos meses; con cuatro hojas, lo hará en el transcurso de un mes.

La deshoja en cualquier grado, indujo una producción más rápida del follaje versus la ausencia de poda, en todas las variedades probadas.

El diámetro del palmito foliar es afectado negativamente por la poda de hojas en proporción al número de hojas que se le permite mantener al tallo $( \pm 4,7 \%$ por hoja).
La variedad Diamantes-10, mostró el menor grado de reinfección después de la deshoja.

La "variedad" Utilis-Tucurrique y Diamantes-20 mostraron una recuperación del follaje ligeramente más rápido que las otras dos variedades.

\section{LITERATURA CITADA}

ARAYA, S. 2004. Optimización de las pruebas de patogenicidad para la confirmación del agente causal de la bacteriosis del palmito de pejibaye (Bactris gasipaes) en Costa Rica. Tesis de licenciatura, Facultad de Microbiología. Universidad de Costa Rica. Costa Rica. 59 p.

ARROYO, C.; MORA-URPÍ, J. 2003a. Relación entre el desarrollo de la hoja guía y el peso del palmito foliar en pejibaye (Bactris gasipaes Kunth). Agronomía Mesoamericana 14(2): 157-164.

.2003b. Aspectos fenológicos del desarrollo en pejibaye (Bactris gasipaes Kunth) para palmito. Agronomía Mesoamericana 14(2): 164-176.

MORA-URPÍ. J. 1999. Poda. In: J. Mora-Urpí.; J. Gainza. eds. Palmito de pejibaye (Bactris gasipaes Kunth) su cultivo e industrialización. San José, Costa Rica. Editorial Universidad de Costa Rica. p. 114-117.

SÁNCHEZ, J. F. 1981. Aspectos fenológicos del pejibaye. Tesis Ing. Agr. Facultad de Agronomía, Universidad de Costa Rica. San José, Costa Rica. 73 p.

SÁNCHEZ, E.; WANG, A.; URIBE, L.; PIZARRO, R.; CHAIMSON, F. P.; VARGAS, L.; BOGANTES, A.; MEXZÓN, R.; ARROYO, R.; MORA URPÍ, J. 2005. Bacteriosis del palmito. San José, Costa Rica. Editorial de la Universidad de Costa Rica. 22 p.

SOLÓRZANO, A.; VARGAS-CARTAGENA, L.; BRAVO, O.; PIEDRA, R.; IWASAWA, H. 2003. Evaluación del fungicida-bactericida Kasurán 50 WP (Kasumin + Oxicloruro de Cobre) contra la bacteriosis (Erwinia 
herbicola) del palmito de pejibaye (Bactris gasipaes). In: A. Solórzano, "Proyecto de generación de tecnología para el manejo de la enfermedad conocida como bacteriosis palmito de pejibaye (Bactris gasipaes k) en Costa Rica". Informe Final Anual. Instituto Nacional de Tecnología Agropecuaria (INTA). San José, Costa Rica, p. 36-44.

VARGAS-CARTAGENA L. 2005. Intervención de Metamasius hemipterus Olivier (Coleoptera, Curculionidae) en el proceso infectivo de la bacteriosis del palmito Erwinia sp. In: XLV Annual Congress of the American Phytopathological Society-Caribbean Division. p. 68.
VARGAS-CARTAGENA, L.; SOLÓRZANO, A.; BRAVO, O. 2003. Identificación del agente causal de la enfermedad en medios de cultivo específicos. In: A. Solórzano, "Proyecto de generación de tecnología para el manejo de la enfermedad conocida como bacteriosis palmito de pejibaye (Bactris gasipaes K.) en Costa Rica". Informe final anual. Instituto Nacional de Tecnología Agropecuaria (INTA). San José, Costa Rica. p. 5-7.

ZAMORA, L. G. 2003. Determinación de la etiología de la "bacteriosis del palmito de pejibaye (Bactris gasipaes) en Costa Rica”. Tesis de Licenciatura. San José, Costa Rica. Facultad de Microbiología. Universidad de Costa Rica. 41 p. 